\title{
A focus on partisanship: How it impacts voting behaviors and political attitudes
}

\author{
Aradhna Krishna ${ }^{\mathrm{a}, *}$, Tatiana Sokolova ${ }^{\mathrm{b}}$ \\ ${ }^{a}$ University of Michigan, 701 Tappan Ave., Ann Arbor, MI 48109, USA \\ ${ }^{\mathrm{b}}$ Tilburg University, 2 Warandelaan, Tilburg, 5037 AB, Netherlands
}

Accepted by Sharon Shavitt, Area Editor

Received 12 July 2017; received in revised form 22 July 2017; accepted 22 July 2017

Available online 25 July 2017

\begin{abstract}
The target article by John Jost (2017 - this issue) focuses on political ideology (liberalism vs. conservatism) and its association with personal characteristics, cognitive processing style, and motivational interests. Jost's arguments and data are very compelling and will inspire consumer psychologists to do more research in the political domain. To enable this goal further, we complement the target article by focusing on partisanship, another major determinant of political judgments and decisions. Whereas political ideology refers to people being more liberal or conservative, partisanship refers to how strongly people identify with a specific political party (e.g., Republicans or Democrats). In reviewing the literature on partisanship, we concentrate on voting behaviors and attitudes, an area not addressed by Jost, but of great importance for consumer psychologists given the large expenditures on political advertising. Adding to Jost's discussion of the link between political ideology and systematic processing, we examine the interplay between these two constructs and partisanship.
\end{abstract}

(C) 2017 Society for Consumer Psychology. Published by Elsevier Inc. All rights reserved.

Keywords: Partisanship; Voting; Political persuasion

\section{Introduction}

"I am a Christian, a conservative, and a Republican, in that order." Mike Pence, the 2016 Republican vice presidential candidate, used this phrase to introduce himself on numerous occasions, including his vice-presidential nomination acceptance speech at the Republican National convention. Similarly, Tim Kaine, the 2016 Democratic vice presidential candidate, repeatedly defined himself in terms of his political ideology, with one of his earlier Senate campaign ads titled "Conservative". As John Jost explains in his target article (2017 - this issue), political ideology (liberal/conservative; left/right) refers to a set of beliefs, opinions, and values that shape how people interpret their

DOI of original article: http://dx.doi.org/10.1016/j.jcps.2017.07.003.

* Corresponding author.

E-mail addresses: aradhna@umich.edu (A. Krishna), t.sokolova@uvt.nl (T. Sokolova). environment and how they think it should be structured. The target article convincingly shows that conservative (vs. liberal) ideology is strongly associated with an array of personality characteristics (e.g. conscientiousness and orderliness for conservatives; compassion and openness for liberals) and motivational interests (e.g. pertaining to stability vs. instigating change) (Jost, 2017). It is therefore not surprising that many politicians emphasize their ideology when communicating with the electorate: political ideology carries a lot of information about political candidates and can exert substantial influence on voters' behaviors.

Interestingly, some politicians choose to define themselves in terms of their party affiliations, rather than their ideologies. For instance, Frederick Douglas defined himself as a "Republican," and Franklin Roosevelt - as "Christian, and a Democrat." Because party affiliation is often correlated with conservative/ liberal ideology, partisan cues potentially inform voters about the politician's ideological stance. However, partisan cues also capitalize on the partisan identification of the electorate. Partisan 
identification, or partisanship, refers to how strongly people identify with a specific political party; and denotes a long-standing, affective, psychological link towards that party (e.g. Democrats or Republicans in the U.S.; Campbell, Converse, Miller, \& Stokes, 1960). Holding the ideology of a candidate fixed, partisan voters are more likely to support that candidate if he belongs to their party (Bankert, Huddy, \& Rosema, 2017; Hawkins \& Nosek, 2012).

To further illustrate the difference between political ideology and partisanship, imagine that Peter is a conservative who identifies strongly with Republicans, whereas Paul is a conservative who does not think of himself as Democrat or Republican, or affiliated strongly with any other party. In this case, Peter and Paul have similar ideologies, but whereas Peter is strongly partisan (Republican), Paul is non-Partisan. As such, Paul may feel less compelled (compared to Peter) to support a Republican candidate who holds liberal values at odds with his own conservative ideology.

The target article (Jost, 2017 - this issue) will inspire and enable consumer psychologists to do more work in the political domain. To facilitate this goal further, we complement the target article by focusing on partisanship and its role in political judgments and decisions. In reviewing the literature on partisanship, we zoom in on voting behaviors and political attitudes, areas not discussed by Jost, but of great importance for consumer psychologists given the large expenditures on political advertising ${ }^{1}$ - e.g., Hillary Clinton's campaign spent \$211.4 million on television advertising between June and October 2016 alone.

Marketing scholars have already started working in the domain of political persuasion (Adaval, Isbell, \& Wyer, 2007; Ahluwalia, 2000; Hedgcock, Rao, \& Chen, 2009; Kim, Rao, \& Lee, 2008; Klein \& Ahluwalia, 2005). We have as well: we studied why the polls went wrong in the 2016 U.S. election (Krishna, 2016), and examined how people make voting decisions when they dislike presidential candidates (Sokolova \& Krishna, 2017). Yet, there remains a large scope for research by consumer psychologists in the area of political decision-making and political persuasion.

We start by discussing how partisanship impacts voting behaviors and political attitudes, and why it does so. We then add to Jost's discussion of the association between political ideology and processing style, by examining the interplay between political ideology, partisanship, and systematic processing. We conclude with a discussion of research directions stemming from this dialogue.

\section{Partisanship and voting behaviors}

Research accumulated over more than five decades shows that partisanship influences voting by affecting voter turnouts and decisions between specific candidates (Campbell et al., 1960; Hawkins \& Nosek, 2012; Petersen, Skov, Serritzlew, \& Ramsøy, 2013; Schaffner \& Streb, 2002). Similar to research on political ideology summarized in the target article, analyses

\footnotetext{
${ }^{1}$ https://www.fec.gov/data/
}

of partisanship and voting behaviors utilized both self-reports and actual voting data, obtaining similar results across the two data types (Bartels, 2000; Miller, 1991; Moore, 2004; Schaffner \& Streb, 2002; Schaffner, Streb, \& Wright, 2001; Sen, 2017). Below we discuss these findings in detail.

\section{Voter turnout}

\section{Higher voter turnout}

Partisanship can increase voter turnout in multiple ways. First, partisanship is rooted in group attachment, or group identification (Binning, Sherman, Cohen, \& Heitland, 2010; Campbell et al., 1960; Dickerson \& Ondercin, 2017; Greene, 1999; Petersen et al., 2013). Research suggests that group identification can serve as a powerful motivator to act in line with the interests and expectations of the group (Goldstein, Cialdini, \& Griskevicius, 2008; Terry \& Hogg, 1996). Following this logic, partisanship, as a form of group identification, can stimulate voting because casting a vote for one's party provides a clear benefit for the group.

Second, partisanship is associated with reduced decision difficulty. It provides a mental shortcut for making voting decisions: by merely looking at candidates' party affiliations, partisan voters get information about the alignment of the candidates' program with their values and interests (Bullock, 2011; Gant \& Luttbeg, 1987; Lau \& Redlawsk, 2001; Mérola \& Hitt, 2015; Rahn, 1993). Additionally, partisan labels make the candidates more discriminable in the eyes of the public (Heit \& Rubinstein, 1994; Mogilner, Rudnick, \& Iyengar, 2008; Sloutsky, 2003). Consumer psychologists have shown that low decision difficulty and high option discriminability both lead to lower decision deferral rates (Dhar, 1996, 1997; Mogilner et al., 2008). Consequently, we could expect that partisanship, by virtue of reducing voting decision difficulty and increasing candidate discriminability, should reduce voting deferral and increase voter turnout.

Several studies support this reasoning. Schaffner and Streb (2002) report that people were more likely to express vote preferences in a survey when vote-choice questions provided party labels, compared to when they did not, and the effect was especially pronounced among less educated respondents. This pattern also emerges in actual voting. Schaffner et al. (2001) examined real election data and found that voter turnout was suppressed in non-partisan elections in the U.S. For example, voter turnout went down following the switch from partisan to non-partisan elections (i.e. having vs. not having candidates' party affiliations on the ballot) in Asheville (NC) in the 1990's, and went up following the switch from non-partisan to partisan elections in Minnesota in the 1970's. In sum, partisanship affects voting behavior by mobilizing citizens to exercise their right to vote.

\section{Voting decisions}

\section{Diagnostic cue}

In addition to mobilizing voters, partisanship can potentially improve voters' decisions because candidates' party affiliations 
carry information about their positions on policy issues (Gant \& Luttbeg, 1987; Lau \& Redlawsk, 2001; Mérola \& Hitt, 2015; Rahn, 1993). When it comes to making decisions in the voting booth, voters may no longer recall each candidate's policy stances. However, they can use candidates' party affiliations to infer which candidate would best serve their interests. Analyses of U.S. presidential election data for the period 1952-1980 (Miller, 1991) and presidential and congressional election data for 1952-1996 (Bartels, 2000) suggest that candidates' party affiliations indeed support voting decisions: the number of voters who identified themselves as Republicans or Democrats in a given electoral cycle is a significant predictor of electoral outcomes. A more recent Gallup survey conceptually replicates these results using self-reported data on voting decisions between Bush and Kerry in the 2004 presidential election (Moore, 2004). Although partisanship was not the strongest determinant of choice between Bush and Kerry, it was as influential in predicting voters' decisions as the candidate's perceived ability to manage the government effectively and his perceived honesty and trustworthiness.

\section{Smaller role for non-diagnostic cues}

Another reason why partisanship can improve political decisions is its effect on the use of non-diagnostic information. When partisan cues are removed, voters tend to switch to other, often less diagnostic cues, including candidates' incumbency status (i.e., whether a given candidate currently holds the position being voted on) and demographic characteristics, to decide between political candidates. Using real election data, Schaffner et al. (2001) show that non-partisan elections provide significant incumbency advantages, meaning that the candidate currently holding office is more likely to be re-elected when his or her party affiliation is not mentioned on the ballot. Demographic factors, such as race and gender, also gain prominence when people cannot rely on party cues (Kam, 2007; Sen, 2017). Kam (2007) reports that people with positive attitudes towards Hispanics are more likely to support a Hispanic candidate when his or her party affiliation is absent (vs. present). Similarly, Sen (2017) demonstrates that Democrats become more likely to support an African American or a female Supreme Court candidate, whereas Republicans become less likely to support female candidates, when the candidates' party affiliations are not disclosed.

Finally, candidate emotionality can affect voter judgments in the absence of party information. Stroud, Glaser, and Salovey (2005) asked study participants to evaluate a fictitious candidate based on a video of his speech. For half of the participants, the candidate displayed a range of emotions in the video and for another half, the candidate showed little emotion. When the candidate was labeled as a Democrat or a Republican, his emotionality had little effect on participant evaluations. However, in the absence of such labels, participants were more likely to vote for the candidate, liked him more, and perceived him as more competent when the candidate was more emotionally expressive. Taken together, the above findings indicate that in the absence of partisan cues, instead of relying on objective facts, people switch to less diagnostic cues, such as incumbency and emotionality of the candidates.

\section{Biasing effects of partisanship}

Thus far we have been focusing on the positive facets of partisanship: the effect on voter mobilization, the diagnostic value of partisan cues, and their role in attenuating the effects of less diagnostic cues in political judgments. We now move on to the potentially biasing effects of partisanship. Specifically, we discuss how objectively identical information can be perceived differently depending on whether it is associated with partisans' own (vs. opposing) party.

\section{Policy support}

First, people evaluate policy depending on how strongly they identify with the party proposing the policy (Bergan, 2012; Cohen, 2003; Hawkins \& Nosek, 2012; Petersen et al., 2013). For example, Americans who are more likely to identify with the Democratic party are more likely to support a welfare policy, regardless of how generous or stringent the policy is, if the policy has been introduced by a Democrat (vs. Republican), whereas the opposite is true for those more likely to identify with the Republican party (Cohen, 2003). Similarly, Danes who associate more with the left-wing Socialist party are more likely to support an ethnic integration policy when it is proposed by socialists (vs. the right-wing People's Party; Petersen et al., 2013).

\section{Political performance evaluation}

Second, partisanship leads people to evaluate the actions of a given administration differently (Anduiza, Gallego, \& Muñoz, 2013; Bartels, 2002; Christenson \& Kriner, 2017; Huber, Van Boven, Park, \& Pizzi, 2015; Malhotra \& Kuo, 2008). For instance, those identifying themselves more with Republicans evaluated Republican George W. Bush's administration's response to Hurricane Katrina more favorably than those identifying themselves more with Democrats (Huber et al., 2015; Malhotra \& Kuo, 2008). Similarly, those identifying themselves more with Republicans (vs. Democrats) held more positive evaluations of the U.S. economy under Republican President George W. Bush (Bartels, 2002). At the same time, Republican (vs. Democrat) partisans were less likely to support unilateral executive action by the Democratic president Barack Obama (Christenson \& Kriner, 2017); and were less likely to believe that the budget deficit had decreased under Democratic president Bill Clinton (Bartels, 2002). The latter result is especially striking because, unlike questions regarding ethnic integration or the state of the economy, the question regarding a change in budget deficit during a given time period has an objectively correct answer. Yet, partisanship affected judgments for this question as well.

We have discussed several partisanship effects, zooming in on the ways in which partisanship can influence voting behaviors and political attitudes. Given the focus of psychologists on 
process, we now turn to the underlying mechanisms driving these partisanship effects.

\section{Why does partisanship affect voting behavior and attitudes?}

The literature offers two opposing arguments for partisanship effects - a heuristic processing account and a motivated reasoning account. We discuss these next.

\section{Heuristic processing account}

On the one hand, partisan judgments could emerge from heuristic processing. Similar to presenter likeability (Chaiken, 1980) or physical appearance (Alter, Oppenheimer, Epley, \& Eyre, 2007), a candidate's party affiliation is a salient cue that can reduce the need for costly information search for partisan decision-makers. Instead of carefully evaluating which candidates' program is more aligned with the voters' values and interests, voters can use the candidates' party affiliations as a proxy for their respective positions (Aldrich, 1995; Lau \& Redlawsk, 2001; Rahn, 1993; Schaffner \& Streb, 2002). Policy and economic evaluation data (Bartels, 2002; Cohen, 2003) are somewhat aligned with the heuristic processing account of partisanship. For instance, Cohen (2003) shows that even when participants were provided with the specific terms of a welfare policy, they evaluated it based on whether it was favored by Democrats (vs. Republicans), instead of focusing on the policy content. Similarly, 1990-1992 American National Election Studies data indicate that evaluations of the G.W. Bush administration showed significant partisanship effects even among well-informed respondents (Bartels, 2002). Thus, even when more diagnostic data (e.g. policy descriptions, state of the economy under G.W. Bush) were available, people based their judgments on partisan cues, effectively reducing the cognitive costs of decision-making.

Although the notion of partisanship as an effort-minimizing heuristic is intuitively appealing, most convincing empirical support for the heuristic account comes from studies examining the role of systematic processing in partisanship. If partisan judgments are a result of cognitive effort minimization, prompting more effortful systematic processing should attenuate the effects of partisanship. In line with this notion, factors linked to systematic processing, such as motivation and ability to process information, reduce the effects of partisanship on judgment (Mérola \& Hitt, 2015; Mullinix, 2016; Prior, Sood, \& Khanna, 2015). Below we discuss these findings in detail.

\section{Motivation and ability to process information}

Partisan cues become less influential when people are motivated to process additional information about the target of judgment (Mullinix, 2016; Prior et al., 2015). When given a monetary incentive to be accurate, people rely less on the match between their own party affiliation and that of the current presidential administration when assessing the current economic climate (Prior et al., 2015). Similarly, when motivated by the personal relevance of a given issue, people are less likely to rely on partisan cues when evaluating policy (Mullinix, 2016). By the same token, partisan cues become less influential when ability to process non-partisan information is greater (Mérola \& Hitt, 2015): as such, highly numerate people are more likely to focus on the numerical information supporting a policy, versus on which party is presenting that information.

In contrast, when systematic processing is reduced, partisan cues are more likely to affect judgments. For instance, angry (vs. control) Republicans become more lenient in evaluating a Republican administration (Huber et al., 2015). This happens because anger, an emotion associated with certainty, reduces systematic processing and increases the impact of cognitive shortcuts in judgment (Bodenhausen, Sheppard, \& Susser, 1994; Rydell et al., 2008). Consequently, partisanship is more likely to affect judgments of angry (vs. control) decision-makers.

\section{Task type}

Task type (rejection vs. choice) is another factor affecting systematic processing (Sokolova \& Krishna, 2016) and, thus, the role of partisanship in judgment. When making decisions, people can reject the less attractive alternatives (e.g., selecting which candidate they would rather not have as a president) or choose the more attractive ones (e.g., selecting which candidate they would rather have as a president). Rejection triggers the consideration of loss of one (or several) foregone options (Dhar \& Wertenbroch, 2000). In turn, consideration of losses has been linked to greater visual attention (Hochman \& Yechiam, 2011), and more rational decisions in risky choices (Yechiam \& Hochman, 2013) and price evaluations (Chatterjee, Heath, Milberg, \& France, 2000). With loss considerations being more prominent in rejection, rejection decisions lead to more systematic processing compared to choice decisions (as shown by Sokolova \& Krishna, 2016). Applied to the context of partisan judgments, this implies that rejecting the less attractive candidate (vs. choosing the more attractive one) may lead people to become less reliant on partisan cues when voting.

To test this prediction, we asked one group of participants whether they would reject the candidate not from their party, and another group of participants whether they would choose the candidate from their party in the 2016 U.S. presidential election. Consistent with our predictions, people were less likely to rely on the candidate's party affiliation in the rejection (vs. choice) group. Similar to high motivation and ability, a task framed as rejection - which prompted more systematic processing - reduced the effect of partisan cues in judgment.

\section{Social and economic factors}

The effects of social and economic factors parallel those produced by motivation, ability, and task type. For example, analysis of the 1980-2012 American National Election Studies data indicates that as economic conditions deteriorate, partisanship exerts a weaker effect on judgments about the economy (Dickerson \& Ondercin, 2017). Thinking about a negative stimulus, such as a bad economy, prompts systematic information processing (Chatterjee \& Heath, 1996; Houston, Sherman, \& Baker, 1991; Malkoc, Hedgcock, \& Hoeffler, 2013). As such, 
when the economy prompts people to rely on systematic processing, the effect of partisanship diminishes.

In a similar vein, the structure of social networks can affect systematic processing and the strength of partisanship effects. Homogenous (vs. heterogeneous) social networks provide little access to novel information (Aral \& Van Alstyne, 2011) and create little potential for conflict, making systematic processing less likely (Maheswaran \& Chaiken, 1991; Maio, Bell, \& Esses, 1996; Savary, Kleiman, Hassin, \& Dhar, 2015). As a result, homogenous networks should increase the reliance on partisanship. In line with this logic, people supporting Barack Obama (George Bush) supported him even more after a 15-min discussion with a few like-minded others (Keating, Van Boven, \& Judd, 2016). In contrast, discussing issues with dissimilar others reduces the effect of partisanship in attitude formation (Lupton, Singh, \& Thornton, 2015).

\section{Motivated reasoning account}

On the other hand, partisan judgments could be a product of effortful processing, wherein people affiliated with a given party engage in motivated reasoning to reach the desired conclusions (Cohen, 2003; Dickerson \& Ondercin, 2017; Kunda, 1990; Petersen et al., 2013). Similar to the motivated social cognition view of political ideology (Jost, Glaser, Kruglanski, \& Sulloway, 2003), the motivated reasoning account of partisanship implies that people may purposefully rely on partisanship to defend their underlying needs and interests.

Indeed, counter to what the heuristic-processing view suggests and in line with the motivated reasoning view, partisanship is not associated with a lack of interest in or experience with politics. In fact, those more interested in elections and political parties and more knowledgeable about candidates' party affiliations are more likely to be biased by partisanship, compared to their less interested and less knowledgeable counterparts (Baum, 2005; Lodge \& Hamill, 1986; Slothuus \& De Vreese, 2010; Strickland, Taber, \& Lodge, 2011). More (vs. less) politically aware voters are less likely to find the opposing party's candidate likeable, less likely to cross party lines when voting (Baum, 2005), and more likely to follow the opinion of their party in policy evaluations (Slothuus \& De Vreese, 2010). Assuming that high political awareness signals high political involvement, this link between awareness and partisanship tendencies gives support to the motivated reasoning account of partisan identification.

Evidence from response-time studies also corroborates the motivated reasoning account. Petersen et al. (2013) examined participants' response latencies for party-inconsistent policies (e.g. a right-wing party proposing that "Public transportation should be free of charge for the elderly"). To agree with such policies partisans could merely rely on the party cues (i.e. heuristic-processing account), or come up with reasons to support an otherwise disliked policy (i.e. motivated reasoning account). In the case of heuristic processing, agreeing with a policy should take less time than disagreeing with it, in the case of motivated reasoning, the reverse relationship should hold.
The results follow the latter pattern, conforming to the motivated reasoning account of partisanship.

Thus, although one may jump to an immediate conclusion that partisanship effects are driven by effort-minimizing heuristic processing, research suggests that they may in part be a result of effortful motivated reasoning. As such, it appears that both accounts - heuristic processing and motivated reasoning - may explain the use of partisan cues.

\section{Political ideology, partisanship, and systematic processing}

In the previous section, we have elaborated upon the relationship between the use of partisan cues and systematic processing. We argue that when systematic processing is facilitated, the effect of partisan cues is reduced (Dickerson \& Ondercin, 2017; Huber et al., 2015; Lupton et al., 2015; Mérola \& Hitt, 2015; Mullinix, 2016; Prior et al., 2015; Sokolova \& Krishna, 2017). Building on Jost's article, we now expand on the interplay between systematic processing, political ideology, and partisanship in political decision-making.

Jost (2017) suggests that liberal ideology is positively associated with systematic processing. Evidence from over 100 empirical tests shows that liberalism is correlated with higher cognitive reflection, need for cognition, and integrative complexity - all of which signal more systematic processing. In addition to correlational evidence, Jost cites studies supporting a causal link between systematic processing and liberal ideology (Eidelman, Crandall, Goodman, \& Blanchar, 2012; Hansson, Keating, \& Terry, 1974; Thorisdottir \& Jost, 2011; Van Berkel, Crandall, Eidelman, \& Blanchar, 2015), meaning that systematic processing is not only associated with liberal ideology, but can also drive it. Table 1 summarizes findings on the association between systematic processing and liberalism; it then outlines the links between systematic processing and partisanship discussed in the previous section.

\section{Relating political ideology to the use of partisanship cues}

So, how do these two variables impact one another? Based on these literatures, we would hypothesize that liberals should be less prone to fall back on partisan cues in their political decisions (e.g. vote for Democrats), compared to conservatives. In fact, recent trends in political ideology and voting decisions reported by Gallup support this reasoning. Whereas the proportion of liberal Americans has been steadily increasing over the last 10 years (from $19 \%$ in 2004 to $24 \%$ in 2015), ${ }^{2}$ the number of Democratic seats in congress has, in fact, gone down during the same period (from 48 in 2004 to 44 in 2015). ${ }^{3}$

Relatedly, if systematic processing reduces the weight of partisanship, it can increase the relative weight of political ideology (liberal or conservative) in political decision-making. Consider a scenario where voter A is deciding whether to vote for a liberal Republican or a conservative Democrat. Normally,

\footnotetext{
${ }^{2}$ http://www.gallup.com/poll/201152/conservative-liberal-gap-continuesnarrow-tuesday.aspx

${ }^{3}$ https://www.senate.gov/history/partydiv.htm
} 
Table 1

Political ideology, partisanship, and systematic processing.

Political ideology and systematic processing

\begin{tabular}{lll}
\hline Need for cognition & Jost, 2017 & Higher need for cognition among liberals \\
Cognitive reflection & & Higher performance on cognitive reflection test among liberals \\
Integrative complexity & More complex speech preferences among liberals \\
Inhibition of systematic processing & Alcohol intoxication, cognitive load, time pressure, anxiety lead to \\
& more conservative/less liberal views
\end{tabular}

Partisanship and systematic processing

\begin{tabular}{lll}
\hline $\begin{array}{l}\text { Motivation } \\
\text { Ability }\end{array}$ & Mullinix, 2016; Prior et al., 2015 & $\begin{array}{l}\text { Monetary incentives and personal relevance reduce the effect of partisan cues } \\
\text { Numeracy reduces the effect of partisan cues; } \\
\text { Anger increases the effect }\end{array}$ \\
$\begin{array}{l}\text { Task type } \\
\text { Economic factors } \\
\text { Social factors }\end{array}$ & $\begin{array}{l}\text { Sokolova \& Krishna, 2017 } \\
\text { Dickerson \& Ondercin, 2017 }\end{array}$ & $\begin{array}{l}\text { Wejection (vs. choice) decisions reduce the effect of partisan cues } \\
\text { Worsening economic conditions reduce the effect of partisan cues }\end{array}$ \\
\hline
\end{tabular}

voter A will base her decisions on the party affiliation (i.e. Republican vs. Democrat) and political ideology (i.e. liberal vs. conservative) of the candidates - giving some non-zero weight to the two attributes (e.g. $\mathrm{w}_{\text {party affiliation }}=\mathrm{x} ; \mathrm{w}_{\text {political ideology }}=$ $1-\mathrm{x})$. In contrast, under systematic processing, she will focus less on the candidates' party affiliation, thus giving greater relative weight to the candidates' ideologies (e.g. $\mathrm{w}_{\text {party affiliation }}=$ $\mathrm{x}-\mathrm{y} ; \mathrm{w}_{\text {political ideology }}=1-\mathrm{x}+\mathrm{y}$ ). In line with this reasoning, Mullinix (2016) demonstrates that personal values trump partisanship when people make decisions about more (vs. less) important issues (and, thus, should be more likely to rely on systematic processing).

Taken together, studies of the effect of systematic processing related to ideology, and related to partisanship, suggest that systematic processing plays a dual role in political decisionmaking: by directly affecting which ideological values people will rely on, but also by affecting how much people will rely on these values (vs. partisanship) in their decisions. Consider a moderate Democrat voting on whether to raise property taxes. The taxes will finance a local school that wants to bus in students from less wealthy neighborhoods. The raise is proposed by a Republican politician. With more systematic processing, the voter will be more liberal in her ideology and be more likely to support this raise. In addition, the voter will be less partisan, meaning that her support for the raise will not be muted by the fact that the raise is proposed by a Republican. Similarly, if the policy is proposed by a Democrat, the voter will not be more likely to support the raise just because the raise is proposed by a member of the voter's own party. Thus, under systematic processing the decision to support a policy will depend less on which party proposes it and more on whether it is liberal (vs. conservative).

Fig. 1 provides a schematic representation of the dual role of systematic processing in political decisions. Of course, much more research needs to be done on this model.

\section{Conclusion}

There are several takeaways for consumer behavior researchers from the political ideology and partisanship literatures discussed in the current dialogue. First, these literatures provide insight into the mechanisms underlying voting. Given the multimillion dollar expenditures on political advertising, consumer psychologists can benefit from better understanding how voting decisions are made and, more specifically, how political advertising affects these decisions. As stated earlier, between June and October 2016, Hillary Clinton's campaign spent \$211.4 million on television advertising and Donald Trump's campaign spent $\$ 74.0$ million. Over a similar period in 2012, Barack Obama and Mitt Romney spent \$241.5 M and \$158.8 M,

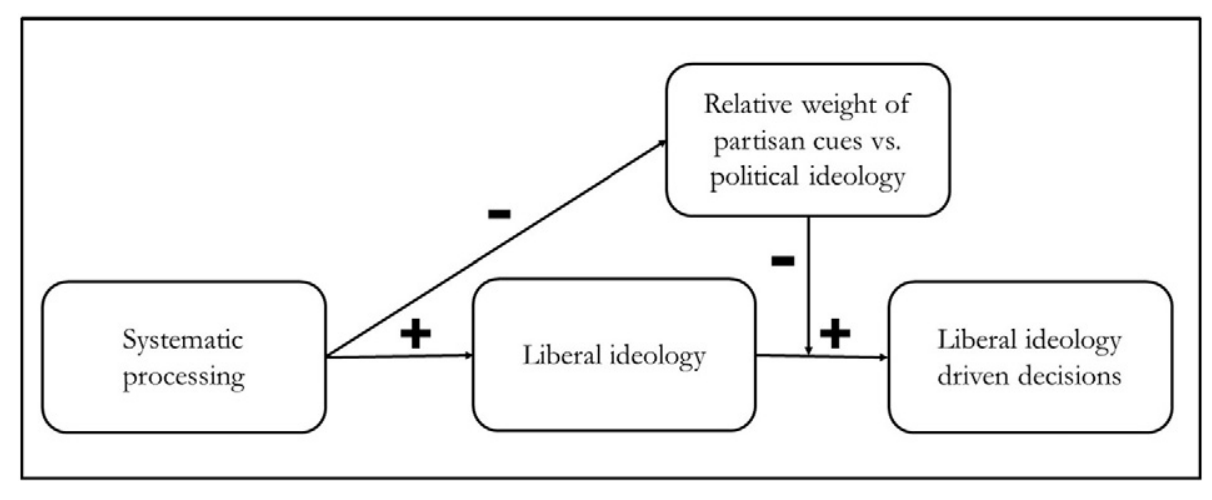

Fig. 1. Political ideology, partisanship, and systematic processing. 
respectively, on television advertising (Goldstein, McCormick, \& Tartar, 2016). It is therefore not surprising that marketing researchers have started analyzing the mechanisms of political persuasion (Adaval et al., 2007; Ahluwalia, 2000; Hedgcock et al., 2009; Kim et al., 2008; Klein \& Ahluwalia, 2005; Krishna, 2016; Sokolova \& Krishna, 2017). However, there is much more room for research by consumer psychologists in the political domain - examining the impact of political ideologies and of partisanship provide two such opportunities.

Second, the current dialogue highlights the role of micro-level factors (e.g. ideology, motivation, personal relevance), as well as more macro-level factors (e.g. social network structures, state of the economy) in shaping individual cognitive processes and decisions in the political context. Although the effects of micro-level factors have been studied extensively in consumer research, the effects of macro-level factors on consumers have received relatively little attention and, thus, present a promising research avenue.

Third, this article touches upon the debate on whether partisanship is driven by the low-effort heuristic processing or by effortful motivated reasoning (Cohen, 2003; Petersen, Giessing, \& Nielsen, 2015; Petersen et al., 2013), and illustrates how response time data can be used to disentangle the two mechanisms (Petersen et al., 2013). Consumer research often uses these mechanisms to explain consumer perceptions and behavior, yet it rarely pits these against one another. For instance, heuristic processing has been used to explain, among others, default option effects (Johnson, Bellman, \& Lohse, 2002), numerical anchoring (Frederick, Kahneman, \& Mochon, 2010), alphanumeric brand evaluations (Gunasti \& Ross, 2010), and spatial perception biases (Krider, Raghubir, \& Krishna, 2001; Raghubir \& Krishna, 1996). Motivated reasoning has been used to explain unhealthy eating behaviors (Hagen, Krishna, \& McFerran, 2016), preferences between hedonic and utilitarian goods (Okada, 2005), outcome-biased product evaluations (Agrawal \& Maheswaran, 2005), and consumer responses to negative publicity (Ahluwalia, Burnkrant, \& Unnava, 2000). More research disentangling and comparing the relative strength of heuristics and motivated reasoning in decision-making would enable a better understanding of the psychological processes driving consumer decisions.

More broadly speaking there are (at least) two ways in which this dialogue can generate additional research by consumer psychologists - using learnings from the political arena within a consumer behavior context, and using learnings from consumer psychology in a political context. We hope that it does both.

\section{References}

Adaval, R., Isbell, L. M., \& Wyer, R. S. (2007). The impact of pictures on narrative-and list-based impression formation: A process interference model. Journal of Experimental Social Psychology, 43(3), 352-364.

Agrawal, N., \& Maheswaran, D. (2005). Motivated reasoning in outcome-bias effects. Journal of Consumer Research, 31(4), 798-805.

Ahluwalia, R. (2000). Examination of psychological processes underlying resistance to persuasion. Journal of Consumer Research, 27(2), 217-232.
Ahluwalia, R., Burnkrant, R. E., \& Unnava, H. R. (2000). Consumer response to negative publicity: The moderating role of commitment. Journal of Marketing Research, 37(2), 203-214.

Aldrich, J. H. (1995). Why parties?: The origin and transformation of political parties in America. University of Chicago Press.

Alter, A. L., Oppenheimer, D. M., Epley, N., \& Eyre, R. N. (2007). Overcoming intuition: Metacognitive difficulty activates analytic reasoning. Journal of Experimental Psychology: General, 136(4), 569.

Anduiza, E., Gallego, A., \& Muñoz, J. (2013). Turning a blind eye: Experimental evidence of partisan bias in attitudes toward corruption. Comparative Political Studies, 46(12), 1664-1692.

Aral, S., \& Van Alstyne, M. (2011). The diversity-bandwidth trade-off. American Journal of Sociology, 117(1), 90-171.

Bankert, A., Huddy, L., \& Rosema, M. (2017). Measuring partisanship as a social identity in multi-party systems. Political Behavior, 39(1), $103-132$.

Bartels, L. M. (2000). Partisanship and voting behavior, 1952-1996. American Journal of Political Science, 35-50.

Bartels, L. M. (2002). Beyond the running tally: Partisan bias in political perceptions. Political Behavior, 24(2), 117-150.

Baum, M. A. (2005). Talking the vote: Why presidential candidates hit the talk show circuit. American Journal of Political Science, 49(2), 213-234.

Bergan, D. E. (2012). Partisan stereotypes and policy attitudes. Journal of Communication, 62(6), 1102-1120.

Binning, K. R., Sherman, D. K., Cohen, G. L., \& Heitland, K. (2010). Seeing the other side: Reducing political partisanship via self-affirmation in the 2008 presidential election. Analyses of Social Issues and Public Policy, 10(1), 276-292.

Bodenhausen, G. V., Sheppard, L. A., \& Susser, K. (1994). Negative affect in social judgment: The differential impact of anger and sadness. European Journal of Social Psychology, 24(1), 45-62.

Bullock, J. G. (2011). Elite influence on public opinion in an informed electorate. American Political Science Review, 105(3), 496-515.

Campbell, A., Converse, P. E., Miller, W. E., \& Stokes, D. E. (1960). The American voter. New York: John Wiley \& Sons.

Chaiken, S. (1980). Heuristic versus systematic information processing and the use of source versus message cues in persuasion. Journal of Personality and Social Psychology, 39(5), 752.

Chatterjee, S., \& Heath, T. B. (1996). Conflict and loss aversion in multiattribute choice: The effects of trade-off size and reference dependence on decision difficulty. Organizational Behavior and Human Decision Processes, 67(2), 144-155.

Chatterjee, S., Heath, T. B., Milberg, S. J., \& France, K. R. (2000). The differential processing of price in gains and losses: The effects of frame and need for cognition. Journal of Behavioral Decision Making, 13(1), $61-75$.

Christenson, D. P., \& Kriner, D. L. (2017). Constitutional qualms or politics as usual? The factors shaping public support for unilateral action. American Journal of Political Science, 61(2), 335-349.

Cohen, G. L. (2003). Party over policy: The dominating impact of group influence on political beliefs. Journal of Personality and Social Psychology, $85(5), 808$

Dhar, R. (1996). The effect of decision strategy on deciding to defer choice. Journal of Behavioral Decision Making, 9(4), 265-281.

Dhar, R. (1997). Consumer preference for a no-choice option. Journal of Consumer Research, 24(2), 215-231.

Dhar, R., \& Wertenbroch, K. (2000). Consumer choice between hedonic and utilitarian goods. Journal of Marketing Research, 37(1), 60-71.

Dickerson, B. T., \& Ondercin, H. L. (2017). Conditional motivated reasoning: How the local economy moderates partisan motivations in economic perceptions. Political Research Quarterly, 70(1), 194-208.

Eidelman, S., Crandall, C. S., Goodman, J. A., \& Blanchar, J. C. (2012). Loweffort thought promotes political conservatism. Personality and Social Psychology Bulletin, 38, 808-820.

Frederick, S., Kahneman, D., \& Mochon, D. (2010). Elaborating a simpler theory of anchoring. Journal of Consumer Psychology, 20(1), 17-19.

Gant, M. M., \& Luttbeg, N. R. (1987). The cognitive utility of partisanship. Western Political Quarterly, 40(3), 499-517. 
Goldstein, N. J., Cialdini, R. B., \& Griskevicius, V. (2008). A room with a viewpoint: Using social norms to motivate environmental conservation in hotels. Journal of Consumer Research, 35(3), 472-482.

Goldstein, K., McCormick, J., \& Tartar, A. (2016). Candidates make last ditch ad spending push across 14-state electoral map. https://www.bloomberg. com/politics/graphics/2016-presidential-campaign-tv-ads/.

Greene, S. (1999). Understanding party identification: A social identity approach. Political Psychology, 20(2), 393-403.

Gunasti, K., \& Ross, W. T., Jr. (2010). How and when alphanumeric brand names affect consumer preferences. Journal of Marketing Research, 47(6), 1177-1192.

Hagen, L., Krishna, A., \& McFerran, B. (2016). Rejecting responsibility: Low physical involvement in obtaining food promotes unhealthy eating. Journal of Marketing Research. http://dx.doi.org/10.1509/jmr.14.0125.

Hansson, R. O., Keating, J. P., \& Terry, C. (1974). The effects of mandatory time limits in the voting booth on liberal-conservative voting patterns. Journal of Applied Social Psychology, 4, 336-342.

Hawkins, C. B., \& Nosek, B. A. (2012). Motivated independence? Implicit party identity predicts political judgments among self-proclaimed independents. Personality and Social Psychology Bulletin, 38(11), 1437-1452.

Hedgcock, W., Rao, A. R., \& Chen, H. (2009). Could Ralph Nader's entrance and exit have helped Al Gore? The impact of decoy dynamics on consumer choice. Journal of Marketing Research, 46(3), 330-343.

Heit, E., \& Rubinstein, J. (1994). Similarity and property effects in inductive reasoning. Journal of Experimental Psychology: Learning, Memory, and Cognition, 20(2), 411.

Hochman, G., \& Yechiam, E. (2011). Loss aversion in the eye and in the heart: The autonomic nervous system's responses to losses. Journal of Behavioral Decision Making, 24(2), 140-156.

Houston, D. A., Sherman, S. J., \& Baker, S. M. (1991). Feature matching, unique features, and the dynamics of the choice process: Predecision conflict and postdecision satisfaction. Journal of Experimental Social Psychology, 27(5), 411-430.

Huber, M., Van Boven, L., Park, B., \& Pizzi, W. T. (2015). Seeing red: Anger increases how much republican identification predicts partisan attitudes and perceived polarization. PLoS One, 10(9), e0139193.

Johnson, E. J., Bellman, S., \& Lohse, G. L. (2002). Defaults, framing and privacy: Why opting in-opting out. Marketing Letters, 13(1), 5-15.

Jost, J. T. (2017). The marketplace of ideology: "Elective Affinities" in political psychology and their implications for consumer behavior. Journal of Consumer Psychology, 27(4), 502-520.

Jost, J. T., Glaser, J., Kruglanski, A. W., \& Sulloway, F. J. (2003). Political conservatism as motivated social cognition. Psychological Bulletin, 129, 339-375.

Kam, C. D. (2007). Implicit attitudes, explicit choices: When subliminal priming predicts candidate preference. Political Behavior, 29(3), 343-367.

Keating, J., Van Boven, L., \& Judd, C. M. (2016). Partisan underestimation of the polarizing influence of group discussion. Journal of Experimental Social Psychology, 65, 52-58.

Kim, H., Rao, A. R., \& Lee, A. Y. (2008). It's time to vote: The effect of matching message orientation and temporal frame on political persuasion. Journal of Consumer Research, 35(6), 877-889.

Klein, J. G., \& Ahluwalia, R. (2005). Negativity in the evaluation of political candidates. Journal of Marketing, 69(1), 131-142.

Krider, R. E., Raghubir, P., \& Krishna, A. (2001). Pizzas: $\pi$ or square? Psychophysical biases in area comparisons. Marketing Science, 20(4), 405-425.

Krishna, A. (2016). Voters' embarrassment and fear of social stigma messed with pollsters' predictions. https://theconversation.com/voters-embarrassmentand-fear-of-social-stigma-messed-with-pollsters-predictions-68640.

Kunda, Z. (1990). The case for motivated reasoning. Psychological Bulletin, $108(3), 480$.

Lau, R. R., \& Redlawsk, D. P. (2001). Advantages and disadvantages of cognitive heuristics in political decision making. American Journal of Political Science, 951-971.

Lodge, M., \& Hamill, R. (1986). A partisan schema for political information processing. American Political Science Review, 80(2), 505-519.
Lupton, R. N., Singh, S. P., \& Thornton, J. R. (2015). The moderating impact of social networks on the relationships among core values, partisanship, and candidate evaluations. Political Psychology, 36(4), 399-414.

Maheswaran, D., \& Chaiken, S. (1991). Promoting systematic processing in low-motivation settings: Effect of incongruent information on processing and judgment. Journal of Personality and Social Psychology, 61(1), 13.

Maio, G. R., Bell, D. W., \& Esses, V. M. (1996). Ambivalence and persuasion: The processing of messages about immigrant groups. Journal of Experimental Social Psychology, 32(6), 513-536.

Malhotra, N., \& Kuo, A. G. (2008). Attributing blame: The public's response to Hurricane Katrina. The Journal of Politics, 70(1), 120-135.

Malkoc, S. A., Hedgcock, W., \& Hoeffler, S. (2013). Between a rock and a hard place: The failure of the attraction effect among unattractive alternatives. Journal of Consumer Psychology, 23(3), 317-329.

Mérola, V., \& Hitt, M. P. (2015). Numeracy and the persuasive effect of policy information and party cues. Public Opinion Quarterly, 80(2), 554-562.

Miller, W. E. (1991). Party identification, realignment, and party voting: Back to the basics. American Political Science Review, 85(2), 557-568.

Mogilner, C., Rudnick, T., \& Iyengar, S. S. (2008). The mere categorization effect: How the presence of categories increases choosers' perceptions of assortment variety and outcome satisfaction. Journal of Consumer Research, 35(2), 202-215.

Moore, D. (2004). "Values" seen as most important characteristic of presidential candidates. http://www.gallup.com/poll/12544/values-seen-most-importantcharacteristic-presidential-candidates.aspx.

Mullinix, K. J. (2016). Partisanship and preference formation: Competing motivations, elite polarization, and issue importance. Political Behavior, 38(2), 383-411

Okada, E. M. (2005). Justification effects on consumer choice of hedonic and utilitarian goods. Journal of Marketing Research, 42(1), 43-53.

Petersen, M. B., Giessing, A., \& Nielsen, J. (2015). Physiological responses and partisan bias: Beyond self-reported measures of party identification. PLoS One, 10(5), e0126922.

Petersen, M. B., Skov, M., Serritzlew, S., \& Ramsøy, T. (2013). Motivated reasoning and political parties: Evidence for increased processing in the face of party cues. Political Behavior, 35(4), 831-854.

Prior, M., Sood, G., \& Khanna, K. (2015). You cannot be serious: The impact of accuracy incentives on partisan bias in reports of economic perceptions. Quarterly Journal of Political Science, 10(4), 489-518.

Raghubir, P., \& Krishna, A. (1996). As the crow flies: Bias in consumers' mapbased distance judgments. Journal of Consumer Research, 23(1), 26-39.

Rahn, W. M. (1993). The role of partisan stereotypes in information processing about political candidates. American Journal of Political Science, 472-496.

Rydell, R. J., Mackie, D. M., Maitner, A. T., Claypool, H. M., Ryan, M. J., \& Smith, E. R. (2008). Arousal, processing, and risk taking: Consequences of intergroup anger. Personality and Social Psychology Bulletin, 34(8), $1141-1152$.

Savary, J., Kleiman, T., Hassin, R. R., \& Dhar, R. (2015). Positive consequences of conflict on decision making: When a conflict mindset facilitates choice. Journal of Experimental Psychology: General, 144(1), 1

Schaffner, B. F., \& Streb, M. J. (2002). The partisan heuristic in lowinformation elections. Public Opinion Quarterly, 66(4), 559-581.

Schaffner, B. F., Streb, M., \& Wright, G. (2001). Teams without uniforms: The nonpartisan ballot in state and local elections. Political Research Quarterly, 54(1), 7-30.

Sen, M. (2017). How political signals affect public support for judicial nominations: Evidence from a conjoint experiment. Political Research Quarterly, 70(2), 374-393.

Slothuus, R., \& De Vreese, C. H. (2010). Political parties, motivated reasoning, and issue framing effects. The Journal of Politics, 72(3), 630-645.

Sloutsky, V. M. (2003). The role of similarity in the development of categorization. Trends in Cognitive Sciences, 7(6), 246-251.

Sokolova, T., \& Krishna, A. (2016). Take it or leave it: How choosing versus rejecting alternatives affects information processing. Journal of Consumer Research, 43(4), 614-635.

Sokolova, T., \& Krishna, A. (2017). The effect of consideration set unattractiveness on decision-making: A study of the U.S. presidential elections. Working paper. 
Strickland, A. A., Taber, C. S., \& Lodge, M. (2011). Motivated reasoning and public opinion. Journal of Health Politics, Policy and Law, 36(6), 935-944.

Stroud, L. R., Glaser, J., \& Salovey, P. (2005). The effects of partisanship and candidate emotionality on voter preference. Imagination, Cognition and Personality, 25(1), 25-44.

Terry, D. J., \& Hogg, M. A. (1996). Group norms and the attitude-behavior relationship: A role for group identification. Personality and Social Psychology Bulletin, 22(8), 776-793.
Thorisdottir, H., \& Jost, J. T. (2011). Motivated closed-mindedness mediates the effect of threat on political conservatism. Political Psychology, 32, 785-811.

Van Berkel, L., Crandall, C. S., Eidelman, S., \& Blanchar, J. C. (2015). Hierarchy, dominance, and deliberation: Egalitarian values require mental effort. Personality and Social Psychology Bulletin, 41, 1207-1222.

Yechiam, E., \& Hochman, G. (2013). Loss-aversion or loss-attention: The impact of losses on cognitive performance. Cognitive Psychology, 66(2), 212-231. 